PHILOSOPHICAL TOPICS

VOL. 26, NO. 1 \& 2 SPRING \& FALL 1999

\title{
Sexism, Racism, Ageism, and the Nature of Consciousness
}

\author{
Ned Block \\ New York University
}

Everyone would agree that the American flag is red, white, and blue. Everyone should also agree that it looks red, white, and blue to people with normal color vision in appropriate circumstances. If a philosophical theory led to the conclusion that the red stripes cannot look red to both men and women, both blacks and whites, both young and old. we would be reluctant (to say the least) to accept that philosophical theory. But there is a widespread philosophical view about the nature of conscious experience that, together with some empirical facts, suggests that color experience cannot be veridical for both men and women, both blacks and whites, both young and old.

Qualia are features of experience that go beyond the experience's representational, functional, and cognitive features. ${ }^{\prime}$ Current debates about whether there are qualia have focused on whether there is anything experiential that goes beyond the representational content of experience. All can agree that there are representational contents of thoughts, for example, the representational content that virtue is its own reward. And friends of qualia, or phenomenists as I will call them. can agree that experiences at least sometimes have representational content too, e.g., that something red and round occludes something blue and square. The recent focus of disagreement is on whether the phenomenal character of experience is exhausted by 
such representational contents. Representationism holds that the phenomenal character of an experience is its representational content. For example, the phenomenal character of an experience as of red consists in its representing something as red. (This view is advanced by Byrne and Hilbert, Dretske, Harman, Lycan, Tye, and less clearly in McDowell. Stalnaker's view is certainly in the spirit of representationism. And representationism is disputed by Shoemaker, Peacocke, and Block.) ${ }^{2}$ I will give an argument that representationism is empirically false. I think the representationist can evade the refutation, but at a cost, so the real upshot will be that representationists are forced to adopt certain problematic views. Some observations about the semantics of color terms will be a by-product of the argument. A sub-theme of the paper is that the facts of individual differences in color perception require some conceptual adjustment.

I can lead into the empirical argument against representationism by a brief discussion of the much-maligned inverted spectrum hypothesis. Even philosophers who smile on qualia often regard the inverted spectrum hypothesis as empirically or conceptually flawed or both. Don't worry, this paper isn't about the inverted spectrum. I'm just using it to lead into my argument. ${ }^{3}$ According to the inverted spectrum hypothesis, things which you and I agree are red-and which our visual experience represents as redlook to you the way things we agree are green look to me. If there are inverted spectra, the dominant philosophical views of the nature of experience are wrong, including representationism. Not surprisingly, it is widely held that the inverted spectrum is a confusion, or if not a confusion, impossible, or if not impossible, not actual. Suppose, for the moment, that spectrum inversion is not only coherent, possible, and actual, but rife. The way red things look to me $=$ the way blue things look to your cousin $=$ the way green things look to your neighbor = the way yellow things look to your mother-in-law. Assuming that I, your cousin, your neighbor, and your mother-in-law all have normal color vision; no one should suppose that red things look red to me but blue to your cousin and green to your neighbor. Any argument that my color vision reveals the way things really look, whereas your cousin and neighbor have color vision that misleads them. could equally well be used by any one of us against the other two. All of us have normal color vision, so none of us systematically misperceives colors in normal or at least in ideal circumstances. But since our experiences that all veridically represent a red thing as red have phenomenal characters that are different from one another, phenomenal character cannot be representational content. Thus, anyone who supposes phenomenal character is identical to representational content has to deny the possibility or coherence or actuality or at least rifeness of such spectrum inversion. ${ }^{4}$ As I noted, there are both conceptual and empirical reasons that make many (though not me) 
suspicious of spectrum inversion, but this paper will consider a phenomenon that evades these suspicions: shifted spectra. Probably, shifted spectra are indeed rife.

As I mentioned, representationists say that the phenomenal character of an experience as of red consists in the experience representing something as red. These representational contents are usually supposed to be "non-conceptual," as distinct from the contents of thoughts. If a cat and I both see a torus (doughnut shape), I may see it as falling under the torus concept, but the cat may not even have the concept of a torus, so the cat's experience cannot represent the torus via that concept. The representational content that is common to my experience and the cat's experience of the torus is the nonconceptual content which consists in representing space as being filled in a certain way. ${ }^{5}$ We concept users can think with such contents, but only by conceptualizing and therefore transforming them. I won't try to spell out the concept of non-conceptual content further. ${ }^{6}$

Another preliminary matter: The inverted spectrum refutes representationism because it is a case of two people whose experiences are representationally alike-they represent something as red-but phenomenally different. But if phenomenal character is included in representational content as a sense component, then the inverted spectrum would not be a case of same representational content but different phenomenal character. For the inverted pair would have experiences with different representational contents. In a forthcoming essay. Burge has suggested that phenomenal character is involved in the individuation of such a sense component but is perhaps not a part of it. ${ }^{7}$ But the representationists I'm after would never accept unreduced phenomenal characters as senses or as involved in individuating senses. The representationism this paper is directed against is referential: the experience as of red consists in its representing something as red.

Although the kind of inverted spectrum needed to refute functionalism requires behavioral (and functional) isomorphism, representationism can perhaps be refuted empirically without these isomorphisms, as I shall now argue. My argument appeals to the fact that color vision varies from one normal perceiver to another. There are three kinds of cone in the retina that respond to long. medium. and short wave light. (Light is electromagnetic radiation in the wavelength zone of $400-700 \mathrm{~nm}$ (nanometers).) The designations "long," "medium," and "short" refer to the peak sensitivities. For example, the long cones respond most strongly to long wavelengths but they also respond to medium wavelengths. Two normal people chosen at random will differ half the time in peak cone sensitivity by $1-2 \mathrm{~nm}$ or more. (More precisely, the standard deviation is $1-2 \mathrm{~nm}.)^{8}$ This is a considerable difference. given that the long wave and middle wave cones only differ in peak sensitivities by about $25 \mathrm{~nm}$. Further, there are a number of specific genetic 
divisions in peak sensitivities in the population that are analogous to differences in blood types (in that they are genetic polymorphisms, discontinuous genetic differences coding for different types of normal individuals). The most dramatic of these is a 51.5 percent $/ 48.5$ percent split in the population of two types of long wave cones that differ by $5-7 \mathrm{~nm}$, roughly 24 percent of the difference between the peak sensitivities of long and middle wave cones. ${ }^{9}$ This characteristic is sex-linked. The distribution just mentioned is for men. Women have smaller numbers in the two extreme categories and a much larger number in between. As a result, the match on the Rayleigh test (described below), as Neitz and Jacobs put it, "most frequently made by female subjects occurs where no male matches."10

Neitz and Neitz, "Molecular Genetics," explain the result as follows. Genes for long and medium wave pigments are on the X chromosome. Men have a single $\mathrm{X}$ chromosome which is roughly equally likely to be either of the two forms, and hence they show a matching distribution with two spikes corresponding to the peak sensitivities of the two kinds of cones. Women have two $\mathrm{X}$ chromosomes. In roughly half the cases, they have the same allele in both chromosomes-in the other half the alleles are different. That is, a quarter of the cases are $\mathrm{X}_{A} \mathrm{X}_{\mathrm{A}}$, a quarter $\mathrm{X}_{\mathrm{B}} \mathrm{X}_{\mathrm{B}}$, and a half are $\mathrm{X}_{\mathrm{A}} \mathrm{X}_{\mathrm{B}}$. In the $\mathrm{X}_{A} \mathrm{X}_{\mathrm{B}}$ case, one gene de-activates the other. But that happens independently in each cone cell in the retina, the result being that the average cell in these women is intermediate between the extreme values, and so these women have long wave absorption peaks roughly in between the two groups of men.

These differences in peak sensitivities don't show up in common activities, but they do reveal themselves in subtle experimental situations. One such experimental paradigm uses the anomaloscope (devised in the nineteenth century by Lord Rayleigh), in which subjects are asked to make two halves of a screen match in color, where one half is lit by a mixture of red and green light and the other half is lit by yellow or orange light. The subjects can control the intensities of the red and green lights. Neitz, et. al note that "People who differ in middle wavelength sensitivity (M) or long wavelength sensitivity (L) cone pigments disagree in the proportion of the mixture primaries required." 1 That is, whereas one subject may see the two sides as the same in color, another subject may see them as different-e.g.. one redder than the other. When red and green lights are adjusted to match orange, women tend to see the men's matches as too green or too red. ${ }^{12}$ Further, variation in peak sensitivities of cones is just one kind of color vision variation. In addition, the shape of the sensitivity curves vary. These differences are due to differences in macular pigmentation, which, as Neitz and Jacobs point out, vary with "both age and degree of skin pigmentation." 13 Hence, races that differ in skin pigmentation will differ in macular 
pigmentation. There is also considerable variation in amount of light absorption by pre-retinal structures. And this factor also varies with age.

I emphasize gender, race, and age to stifle the reaction that one group should be regarded as normal and the others as defective. (That would be sexism, racism, or ageism-hence the title of the essay.) There are standard tests for defective color vision, such as the Ishihara and Farnsworth tests, and it is an empirical fact that most men and almost all women have nondefective color vision as measured by these tests. My point is only that the facts about variation that I have presented give us no reason at all to regard any gender, race, or age as abnormal in color vision.

The fact that people match differently gives us reason to suppose that the phenomenal character of an experience of a narrow shade-say, a specific Munsell chip - may not be the same for any two persons if they differ in sex, race, or age. (The Munsell chips are a set of 1600 one-inch square shade samples organized by hue, saturation, and brightness that are widely used for commercial and scientific purposes.) The differences noted in matching colored lights will presumably also apply to chips that have the same dominant wavelengths as the colored lights, if such chips can be made. There is another sort of evidence for a similar conclusion. Hardin mentions a classic 1968 study of the spectral location of unique green in a group of fifty normal subjects. ${ }^{14}$ (Unique green is green that does not appear to be at all reddish, yellowish, or bluish.) Here is a table of locations:

$\begin{array}{ll}5 \text { subjects located unique green at } & 490 \mathrm{~nm} \\ 11 \text { at } & 500 \mathrm{~nm} \\ 15 \text { at } & 503 \mathrm{~nm} \\ 12 \text { at } & 507 \mathrm{~nm} \\ 5 \text { at } & 513 \mathrm{~nm} \\ 2 \text { at } & 517 \mathrm{~nm}\end{array}$

Note that the $27 \mathrm{~nm}$ span of this group's location of unique green is 9 percent of the visible spectrum. Hardin also mentions a more recent study that indicated a much larger range-from $486 \mathrm{~nm}$ to $535 \mathrm{~nm}, 13$ percent of the visible spectrum. In this study, there was an overlap of $7 \mathrm{~nm}$ for unique green and unique blue. That is, there were lights that some people classified as unique green and others classified as unique blue.

The upshot is that if we take a chip that any one subject in this experiment takes as being unique green, most of the others will see it as at least slightly bluish or yellowish. Thus it is reasonable to say that any given chip will look a bit different to a randomly chosen subject than to most others. And we have no reason to think that this phenomenon is limited to that particular shade of chip. (Although it is a fact that there is less agreement about unique green than about other colors.) Hardin mentions an estimate by Ralph Evans that "a perfect match by a perfect 'average" observer would 
probably be unsatisfactory for something like 90 percent of all observers because variation between observers is very much greater than the smallest color differences which they can distinguish." 15 Thus we are justified in supposing that the way any chip looks (colorwise) is unlikely to be exactly the same as the way that chip looks to most other people, especially if they differ in sex, race, or age.

In sum, there are three arguments for the conclusion that any chip is likely to look different to different people, especially those who differ in sex, race or age. First, there is the fact of variation in relevant aspects of the visual systems of different people. The reasoning here does presuppose a limited form of supervenience. But the supervenience claim involved is a scientific claim about the dependence of experience on absorption curves, not a general metaphysical doctrine that can easily be set aside. Second, the differences in matching give a reason that even a functionalist would have to take seriously. Third, we have the argument just mentioned that appeals to the variation in the location of unique colors.

So now we have the beginnings of an argument against representationism. Jack and Jill both have experience that represents red things as red even though they very likely experience red slightly differently

But the representationist could reply that the representational contents of Jack's and Jill's visual color categories, say that of red, may differ too, so there is still no proven gap between representational content and phenomenal character. Before we can see what justice there is in this complaint, we should briefly examine its perhaps surprising invocation of color categories. "Color categories?" you say. "I thought the representationist was talking about non-conceptual contents?" True, but the representationist has to allow that our visual experiences can represent a scarlet thing as red as well as scarlet. For we can experience scarlet things as both red and as scarlet. We can experience two red things of different shades as having the same color, though not the same shade, so a representationist has to concede a component of the representational contents of experience that captures that fact about experience. The representationist has to allow representational content of both color and shade. Further, pigeons can be conditioned to peck when presented with things of a certain color, as well as of a certain narrow shade. Even if the pigeon lacks color concepts, it has something short of them that involve some kind of categorization of colors as well as shades. red as well as scarlet. Let's use the term "category" for this aspect of the non-conceptual contents that are concept-like but can be had by animals which perhaps can't reason with the contents. Now we can see why the argument I gave against the representationist can be challenged. Jack's and Jill's experiences of a single red fire hydrant may differ in phenomenal character but also in representational content, because, say, Jack's visual cate- 
gory of red may include or comprise a shade that is included instead in Jill's visual category of orange. Furthermore, because of the difference in Jack's and Jill's color vision, the fire hydrant may look more red than orange to one, more orange than red to the other.

The reader may wonder: if Jack's and Jill's visual categories of red differ from one another, how can there be objective (i.e., intersubjectively available) colors? Perhaps there are some things that Jill would categorize as "green" and Jack would categorize as "blue," even in ideal circumstances. And perhaps this difference in color word usage is grounded in a corresponding difference in visual color categories. If so, it is implausible to regard either as mistaken. A sensible conclusion is that they use the words "blue" and "green" in somewhat different senses, both correctly. The objective nature of color, then, derives from the overlap between persons with normal color perception. There are objects which would be categorized as "blue" under ideal circumstances by everyone with normal color vision, and that's what makes them objectively blue. The objects that are not objectively blue, but are categorized as "blue" under ideal circumstances by one normal person but not another are indeterminate in objective color. One aspect of the characterization I just gave is misleading: it makes objective color look more linguistic than it is. In principle, there could be objective color even without language. Our non-linguistic color behavior includes, for example grouping things together in same-color piles. Visual color categories could be externalized in that way even without language. I endorse this point of view, though $I$ shall argue that it is of less value to the representationist than might appear at first glance. ${ }^{16}$

Jack's and Jill's color categories may differ, but must they? That is, does a phenomenal difference require a representational difference? I think the answer is no. Verbal color categories are certainly partly social and the same may be true of visual color categories. Before the introduction of the orange into England, the color of the orange was included in red. Public categorization may make visual color categories more uniform than they would be if each person developed his or her own color categories from scratch. The representationist may suppose that the very evidence that I have appealed to for phenomenal difference also supports representational difference. I noted that location of unique hues differ from person to person. Perhaps Jack will see the colored object they are both looking at as closer to unique red than Jill will. But it remains to be shown that we have visual representational resources capable of expressing such fine grained differences. No doubt there are differences in dispositions which could be made explicit. If a set of ultimately fine-grained chips were set up, perhaps Jack would reckon the sample he and Jill are looking at as 50,003 chips from unique red, whereas Jill would categorize it as 49,901 chips from unique red. But 
these representational resources have been constructed, and the representationist has not shown that such resources are available at the moment of perception, i.e. on the fly.

The argument just given puts the ball in the representationist's court. But it will be of interest to move to a slightly different form of the argument.

Even if Jack's and Jill's visual color categories differ, a wedge between phenomenal character and representational content can be inserted by applying the argument just given to narrow shades rather than broad colors. Let us co-opt the word "aquamarine" to denote a shade of blue that is as narrow as a shade can be, a shade that is the shade of one chip from the densest set of chips that people with normal color perception can distinguish from one another, one that has no discriminable subshades. If Jack's and Jill's visual systems differ slightly in the ways that I described earlier, then we can reasonably suppose that aquamarine doesn't look to Jack the way it looks to Jill. Maybe aquamarine looks to Jack the way turquoise (a different minimal shade, let's say) looks to Jill. But why should we think that there is any difference between the representational contents of Jack's experience as of aquamarine and Jill's? (I will consider some suggestions on behalf of representationists later.) Neither is abnormal and they both acquired their categories of aquamarine by being shown (let's suppose) a standard aquamarine chip. Their visual experiences both represent aquamarine things as aquamarine. Their aquamarine representations can't comprise different shades since they already are minimal shade representations. Alternatively, we can think of Jack's and Jill's representational contents as that shade. Jack's and Jill's representational contents both represent that shade as that shade. Of course, both of their representations are no doubt temporary. (A trained observer can discriminate ten million surface colors. No one has that many permanent shade representations.) But even temporary representations can have content.

The upshot is that there is an empirically based argument for a conclusion-what one might call "shifted spectra"-that, while not as dramatic as an inverted spectrum, has much the same consequences for representationism and for the issue of whether there are uniform phenomenal characters corresponding to colors. There probably are small phenomenal differences among normal perceivers that don't track the colors or shades that are represented. Genders, races, and ages probably differ by shifted spectra. Thus, if representationism is right, if aquamarine things look aquamarine to men, they probably don't look aquamarine to women. And if aquamarine things look aquamarine to one race or age group, they probably don't look aquamarine to others. In sum: If representationism is right, color experience probably cannot be veridical for both men and women, both blacks and whites, both young and old. Hence, representationism is not right. Alternatively, assuming that most men and women, blacks and whites, old and young have veridical color vision, two experiences can have the same 
representational content but different phenomenal character so representationism is wrong (A possible escape route will be mentioned later.)

I mentioned above that there is an objection to my first try at refuting representationism: maybe Jack's visual category that represents red includes or comprises a shade that is included in Jill's visual category that represents orange. (More later on the exact meaning of the terms "includes" and "comprises.") Does the same objection apply to minimal shades themselves? As just mentioned, a minimal shade can't include or comprise any shades other than itself, so it would seem that the problem can't arise. ${ }^{17}$

The shifted spectrum should not disturb the functionalist, however, for even if there are phenomenal differences among representationally identical experiences as just supposed, the phenomenal differences might be revealed in subtle empirical tests of the sort I mentioned. That is, perhaps shifted spectra always result in different matches on a Rayleigh Anomaloscope or other devices. But shifted spectra would still count against representationism.

Should the phenomenon I'm talking about really be called a "shifted spectrum"? One way in which the name is appropriate is that the Munsell 4 Red chip may look to Jack the way the 5 Red chip looks to Jill. But there is one misleading implication involved in calling the phenomena I describe as a "shifted spectrum," namely, that there is no reason to believe that there is any sort of uniform displacement of the color wheel, a mini version of the traditional inverted spectrum. Differences in absorption peaks for long wave cones, for example, would be expected to cause differences that are more "ragged" than that.

\section{REPRESENTATIONIST OBJECTIONS}

I will put an objection in the mouth of the representationist:

Whatever the differences in their visual systems, if Jack and Jill are normal observers, then in normal (or anyway ideal) conditions, the standard aquamarine chip has to look aquamarine to Jack and it also has to look aquamarine to Jill. After all, "looks aquamarine" just means that their perceptual contents represent the chip as aquamarine, and you have already agreed (above) that both Jack's and Jill's visual experience represent the chip as aquamarine. You have argued that the representational content of their visual experience is the same (viz., aquamarine), but the phenomenal character is different. However, we representationists don't recognize any kind of phenomenal character other than that which is given by the representational content-which is the same for Jack and Jill.. The chips look aquamarine to both Jack and Jill, so they look the same to both Jack and Jill, so Jack and Jill have the same phenomenal characters on viewing the 
chips in any sense of "phenomenal character" that makes sense. If Jack and Jill have different brain states on viewing the aquamarine chip, that just shows that the different brain states just differently realize the same phenomenal character.

Reply: We phenomenists distinguish between two senses of "looks the same." In what Shoemaker calls the intentional sense of "looks the same," the chips look the same (in respect of color) to Jack and Jill just in case both of their perceptual experiences represent it as having the same color. ${ }^{18}$ So I agree with the objection that there is a sense of "looks the same" in which the aquamarine chip does look the same to Jack and Jill. But where I disagree with the objection is that I recognize another sense of "looks the same" (the qualitative or phenomenal sense), a sense geared to phenomenal character, in which we have reason to think that the aquamarine chip does not look the same to Jack as to Jill. (The same distinction is made in somewhat different terms by Shoemaker, Peacocke, and Jackson. ${ }^{19}$ But the case at hand supports the phenomenist rather than the representationist. For we have reasons to believe that there is a sense in which the aquamarine chip does not look the same to Jack as to Jill. One reason was given earlier: the chip that Jack regards as unique green (green with no hint of blue or yellow) is not regarded as unique green by most other people. So it looks different to Jack from the way it looks to most others, including, we may suppose, Jill. And the same is likely to be true for other chips, including the aquamarine chip. Another reason was given earlier, one that even functionalists should agree to: Jack and Jill match differently on the anomaloscope. Recall that the match "most frequently made by female subjects occurs where no male matches." If Jack produces a mixture of blue and green which he says matches the aquamarine chip, Jill will be likely to see that mixture as either "bluer" than the chip or "greener" than the chip.

The big difference of opinion on the topic of the nature of experience is between those who accept and those who reject qualia; that is, features of experience that go beyond the experience's representational, functional, and cognitive features. The argument I just gave depends in part on using functionalism against representationism. The functional differences between different perceivers suggest phenomenal differences, but we have yet to see how those phenomenal differences can be cashed out representationally, even if they can be cashed out functionally. So the argument does not show that there are qualia, though it does go part way, by challenging one of the resources of the anti-qualia forces.

Another Representationist Objection:

These empirical facts show that colors are not objective (in the sense of intersubjectively available). A given narrow shade looks different to different groups, so the different groups rep- 
resent it as having slightly different colors. Thus it does in fact have slightly different colors relative to these different groups. Famously, phenylthiocarbamide tastes bitter to many people but not to many others. Phenylthiocarbamide is not objectively bitter, but it is objectively bitter relative to one group and objectively non-bitter relative to another. Color is the same, though not so dramatically. There are no absolute colors-color is relative, though only slightly so. You have argued that Jack and Jill represent a given chip as the same objective shade even though they experience that shade differently. But if there are no objective shades, your argument collapses.

Reply: The problem with this objection derives from a difference between our concept of taste and our concepts of at least some colors, or rather shades. We are happy to agree that phenylthiocarbamide has no objective taste-it tastes bitter to some but not others. But we do not agree that Munsell color chip 5 Red has no objective hue. Its objective hue is 5 Red no matter whether it looks different to people of different genders, races, and ages. The whole point of the Munsell color scheme, the Optical Society of America Uniform Color Space, and other color schemes, as Hardin points out, is to catalog objective shades. ${ }^{20}$ Every American grade-school child knows the shades named by the Crayola company, despite differences in the way Burnt Sienna or Brick Red probably look to different children. If you paint your living room wall Benjamin Moore Linen White, it is an objective fact that you have not painted it Cameo White, Dove White, Opal White, or Antique White. If you have ordered White 113, but the paint store gives you White 114, you can get your money back. (The premixed colors have names in the Benjamin Moore scheme; the custom colors, of which there are very very many, as anyone who has ever picked out one of their paint colors knows, have numbers.) If the paint dealer says "Hey, color is relative to gender and we are different genders. Your white 113 is my 114 , so I didn't make a mistake," he is wrong. In short, there are at least some objective colors, the shades systematized by the various organizations mentioned above.

Another representationist objection:

Your point depends on special regimented objective color systems such as the Munsell or OSA system or commercial paint company systems. You say that if Jack and Jill are looking at Benjamin Moore chip Green 121 and their visual experiences are representing it as that very shade, still it will probably look different to them. Same representational content, different phenomenal character-according to you. But the existence of these regimented systems does not make our normal, everyday color categories disappear. Perhaps the chip looks bluish green to Jack but greenish blue to Jill, in which case we have a representational difference. So you don't have a case of same representational content, different phenomenal character after all. 
Reply: The objection assumes a case in which the phenomenal difference between Jack and Jill results in a verbal disagreement, one saying "greenish blue," the other saying "bluish green." First, note that there is no reason to suppose that the phenomenal character of a perception of a thing of a specific shade must also represent it as having a less specific color. Ignoring this point, suppose instead that Jack and Jill agree! Suppose that they are looking at a chip_-say Benjamin Moore Green 126-that they both categorize as "greenish blue." The representationist doesn't get to make up my thought experiment. Even one case of same representational content/ different phenomenal character is enough to make my point against the representationist, even though there are other similar thought experiments that don't make the point. Will there be any chips on which Jack and Jill have verbal agreement? Boynton estimates that a maximally fine grained set of color chips would have about a million chips. ${ }^{21}$ "Blue-green" is one of ten categories in the Munsell system, so a rough estimate of how many chips of blue-green hue there would be if the system were maximally fine grained is about 100,000 . Of those, we might suppose that half would fall into greenish blue and half into bluish green. So there are somewhere in the vicinity of 50,000 different chips that would be widely agreed to be greenish blue. Though this is a back-of-the-envelope calculation. I think the upshot is clear: we can safely assume that there will be very many chips for which Jack and Jill will have no verbal disagreement. In these cases in which Jack's and Jill's verbal categorizations of a chip are the same, what will the representationist appeal to in order to justify a representational difference?

Any given chip is likely to look different to Jack from the way it looks to Jill. And we are considering one of the many cases where Jack and Jill have no verbal disagreement about the color of the chip. How can the representationist justify a representational difference? Here is one approach the representationist might try. Let us assume that human color experience represents colors via a combinatorial apparatus that we can think of as in an internal language, mentalese. In appropriately ideal circumstances, when someone says they are seeing something as "greenish blue," their visual system represents it as GREENISH BLUE (mentalese is capitalized English). Both Jack's and Jill's visual systems represent Green 126 as GREENISH BLUE. The apparatus can be used by the representationist to explain or at least accommodate the fact that Green 126 looks different to them. Perhaps, despite verbal agreement, one has the representation "GREENISH SIDE OF GREENISH BLUE" whereas the other has "BLUISH SIDE OF GREENISH BLUE." Maybe they could be brought to say something like that in English. But how far can such an apparatus be pushed? What if Jack and Jill agree on "bluish side of greenish blue"? Will the representationist postulate different mentalese representations of ever-increasing complexity? Remember there are on the order of 50,000 "greenish blue" chips. Whatever plausibil- 
ity attached to the introduction of the mentalese color term apparatus in the first place derived from the idea that there was something in our visual experience that corresponded to combining "green" and "blue," but that plausibility quickly dissipates as the representations get further from anything that one can get an explicit handle on.

The upshot is that there probably are many chips on which Jack and Jill can agree on the verbal description, but which still look different to them. The challenge to the representationist is to tell us why we should not see such cases as cases of same representational content, different phenomenal character. $^{22}$

\section{SUBJECTIVE COLOR}

Except very briefly early in the paper, when I considered the possibility that Jack's and Jill's visual categories of red might differ, I have been supposing objective color representations (shared by normal perceivers in virtue of being normal) as I think representationists also suppose. However, there is a problem with objective color representation in the light of the facts about individual variation: an objective sense of "looks red" has to give up one or the other of two plausible principles. The two principles are:

(1) If something looks red under conditions that are as ideal as can be, it is red.

(2) One can tell whether something looks red "from the inside" without need of a survey of the judgments of others, so long as the conditions of perception are as ideal as can be.

Suppose something looks red to me in conditions that are as ideal as can be. I consult others and determine that normal perceivers in ideal conditions disagree about whether it is red. It follows that the item is not objectively red. Thus looking red to me is not sufficient for being red. There are two possibilities: Looking red to me (even under ideal conditions) isn't sufficient for looking red, or looking red (even under ideal conditions) isn't sufficient for being red. Both options reveal a counterintuitive aspect of objective color in the light of the facts about individual variation. I would suppose that any view that takes colors as objective will have to embrace the former, holding that data about all normal perceivers is required to find out whether something looks red even under ideal conditions (giving up on (2)). In effect, the objective view of color will have to regard "looking red" as looking red to all normal perceivers, and that is something I cannot ascertain simply by looking at something, even if I am a normal perceiver and know I am and conditions are ideal and known to be so. (Note that switching from "all" to "most" won't help.) I can tell by looking whether something looks red to me 
but not whether it looks red, simpliciter. Thus, in the light of the facts about individual variation, looking red, where red is an objective color is not what one might have supposed-it is not an observational concept but rather a social concept. One assumes naturally that the properties one detects in color perception are both observational and objective-the same color properties that are detected by others-but if this argument is right they can't be both.

We should not suppose that this is a conclusive reason for preferring subjective color to objective color, since the former has its own peculiarities, but it does motivate taking a closer look at subjective color.

There is a second reason for taking a closer look at subjective color. Here is a version of my argument against representationism:

1. Jack's and Jill's perception is equally veridical; they see colors as they are (in ideal circumstances).

2. Their experiences of chip Green 126, a single objective shade, are different, even in ideal circumstances.

3. If phenomenal character $=$ representational content, chip Green 126 is colored all over at the same time with 2 different colors or 2 different shades of one color.

4. Perhaps this is impossible. In any case, Green 126 has one shade, viz., Green 126. so representationism is wrong.

Putting the argument in this way points to an obvious representationist response: that Jack and Jill represent the chip has having one objective color, Green 126, but that they represent it also as having different subjective person-relative colors.

Let us suppose that each person has visual color categories and corresponding color terms that differ slightly from the color categories of some others. For example, Jack's visual category of red and hence Jack's sense of "red" may differ from Jill's, comprising somewhat different minimal shades. But person relative color categories can be used against the reply I just gave to the representationist. If Jack and Jill have visual experiences that represent the chip as (as they would each say) "on the greenish side of greenish blue." and if Jack and Jill have different categories of "green" and "blue," then there is a representational difference between them despite their verbal agreement. "On the greenish side of greenish blue" has compositional semantics. If the meanings of Jack's "green" and "blue" differ from Jill's, so do their meanings of "on the greenish side of greenish blue." As I mentioned early on in the paper, Jack's and Jill's visual color categories may differ, but that doesn't show they must differ, even if their phenomenal characters differ. The grid of public use of color terms and public categorization may impose a certain degree of uniformity on people's color categories. All I need is a mismatch between representational content and phenomenal character, and I have made a prima facie case. The representationist response that visual color categories may differ does not seem to me to be an adequate reply. 
But even supposing it is adequate, the move to subjective color does not get the representationist out of the soup. The same problem arises in a slightly different form. Recall that Jack and Jill are looking at Green 126, which they describe in exactly the same way verbally (e.g., "on the greenish side of greenish blue"). But they differ, we are supposing, in the shades comprised, and therefore the contents of their words "green" and "blue" and the corresponding visual categories. But note that we can also expect them to describe Green 127 in exactly the same way. Recall that by my back-ofthe-envelope calculation, there are roughly 50,000 distinct ultimately finegrained chips that are in some sense a "bluish green" category. But now we can ask the question: what is the representational content of Jill's experience of Green 126 and Jill's experience of Green 127 such that there is a representational difference between them? We can't appeal to any difference in her contents of "green" and "blue" since they remain the same. As earlier, we could impose a representational system of ultimately fine-grained chips which Jill could use to represent the difference, but that doesn't show that she has that representational system on the fly. Alternatively, we could postulate a mentalese difference as before. Her representation of Green 126 is "ON THE GREENISH SIDE OF THE GREENISH SIDE OF GREENISH BLUE" whereas her representation of Green 127 is "ON THE BLUISH SIDE OF THE GREENISH SIDE OF GREENISH BLUE." But this is no more plausible in the intrasubjective comparison than it was in the case of the intersubjective comparison made before.

I put the question for the representationist in a stilted way to avoid misunderstanding of it: What is the representational content of Jill's experience of Green 126 and Jill's experience of Green 127 such that there is a representational difference between them? The question consists of 3 parts:

1. What is the content of Jill's visual representation of Green 126 ?

2. What is the content of Jill's visual representation of Green 127 ?

3 . In terms of 1 and 2, what is the difference?

It is no good just saying something like "Green 127 looks slightly greener to Jill than Green 126," without saying what the content of her representation of each chip is such that that is the difference. The challenge to the representationist is to say what these contents are in a way that accommodates the difference.

The link between the intra-subjective case and the intersubjective case can be made explicit by noting that the difference between Jack's and Jill's experience of Green 126 could be the same as the difference between Jill's experience of Green 126 and Green 127. If the complicated apparatus of mentalese predicates could be harnessed to accommodate one, then presumably it could be harnessed to accommodate the other. But both are unsupported empirical speculations. 
No doubt there is a tacit color space as revealed in similarity judgments and as systematized in the color solid. And as adults who know about it, we can achieve imaginal access to it. But that is a far cry from evidence that phenomenal awareness of such a space is part and parcel of color perception, something which I doubt. For example, is the color experience of monkeys and babies informed by such a space? My argument is an empirical one and this is an area of empirical vulnerability.

In sum, I have not been able to imagine a representationist objection that gives me any good reason to depart from my earlier conclusion that representationism is probably empirically false. Of course the representationist side of the dialectic has been up to me, and real supporters of the view may see their portion of the dialectic rather differently than I have on their behalf. So we should regard the arguments I have given as a challenge to them. I now turn to the one consideration in the literature that I know of concerning issues of this sort.

Byrne and Hilbert, in a defense of representationism, ${ }^{23}$ discuss the objection that one subject might locate unique green ${ }^{24}$ at $490 \mathrm{~nm}$, whereas another might locate it at $520 \mathrm{~nm} .^{25}$ Their defense makes two points. First, they appeal to the analogy of the square and the diamond. It would seem at first glance that nothing could be both a square and a diamond, but once one sees that a tilted square is a diamond, on second thought, the two properties are compatible. Similarly, they suggest, perhaps "some ways of being unique green are also ways of being bluish green." ${ }^{26}$ Byrne and Hilbert see themselves as floating a possibility, and so they give no hint as to how the square/diamond analogy could possibly apply to color. (They appear to have objective color in mind, otherwise it would be trivial that something could be unique green-relative to one person, yet bluish green-relative to another.) But then it is hard to see why we should take that possibility seriously. Further, even if it applies to colors, there would be a further burden on them to show how it could apply to minimal shades. Byrne and Hilbert conclude their discussion (and this is the second point) of this matter as follows: "But even if bluish green and unique green are in fact contraries, this is not a disaster. That many of us misperceive unique green objects is certainly an unwelcome result; but at least (for all the objection says) we veridically perceive them as green, and perhaps that is enough." ${ }^{27}$ But what is the rationale for taking some locations of unique green to be veridical and others as misperceptions?

Byrne notes in correspondence that I concede that the individual differences in color vision that $I$ have been talking about result in some indeterminacies about the objective shade of some mixtures of light. (See the following two sections.) He wonders why this fact doesn't count in his favor. I conceded that there are some objects whose fine-grained shade is 
indeterminate, but there are many whose fine-grained (objective) shade is not indeterminate. Any of us can see huge numbers of them in a paint store. If Jack and Jill are both looking at Benjamin Moore Red 123, they can agree on the objective fact that that is what shade it is, even though very likely their phenomenal experience of it will be slightly different. Even a single example of experiences that have the same representational content but different phenomenal character is enough to disprove representationism.

\section{REPRESENTATIONISM'S LAST AND BEST CHANCE}

Suppose that Jack and Jill are looking at the aquamarine chip in ideal circumstances. Their experiences represent it as aquamarine or as "that shade," but the phenomenal characters of their experiences differ, hence representationism is false. So I have argued. But it should be noted that one of the items of evidence that I presented for the different phenomenal characters of their experiences was different matching experiences and behavior. Thus we may suppose that there is a mixture of colored lights that Jack takes as matching the aquamarine chip but Jill takes as not matching it. So, it seems, the idealized extensions of their terms "aquamarine" or their visual categories indicated by "that shade" as applied to the aquamarine chip are different. Jack's includes the mixture of lights and Jill's does not. So their contents are different. Hence my argument appears to be refuted.

The argument just mentioned was my second one, but the response against the second argument can be used against the first one. The difference, you will recall, was that the first was based on broad colors, the second on narrow shades. The first argument supposed that Jack's and Jill's experiences both represented something as red, but were nonetheless phenomenally different. But it is open to the representationist to argue that one only sees something as red via seeing it as a particular shade of red, so if there is bound to be a difference in the shade content, that could be the source of the difference in phenomenal character of the broad color experience.

Representationists say the phenomenal character of the experience as of red consists in a visual state representing something as red. They depend on the fact that in color experience a property is represented. But what property would be involved if the objector's point of view is right? Here is one option: Two representations represent the same property for a person just in case they would be applied by that person to exactly the same things in ideal circumstances. Or perhaps the representationist would prefer a vaguer alternative. The subjective extensional criterion could be taken as merely a sufficient condition of difference: If two representations would be applied to different objects in ideal circumstances, then the properties represented are 
different. The distinction is more promissory than actual, although the representationist is invited to make the view less vague. In the absence of a representationist proposal, I will use the biconditional form. Thus the view is a version of extensionalism in that content is a matter of idealized extension. And it is a form of subjectivism in that a person's color and shade contents are a matter of that person's idealized applications of color and shade properties. I will call the view "subjective extensionalism." (Of course, subjective extensionalism is a form of representationism, but I will tend to leave out the "representationism" for brevity.)

One line of reply to the subjective extensionalist (representationist) would be to deny that the mixture of lights is part of Jack's or anyone else's extension of the visual category of aquamarine. Jill makes a finer discrimination and sees a shade (or at least a shade difference) that Jack does not see, a different shade from aquamarine. The mixture of lights is not aquamarine at all, but a distinct shade that Jack cannot distinguish from aquamarine. On this view, ultimately fine-grained shade distinctions should distinguish shades that can be distinguished by some normal perceivers in optimal circumstances, even if other normal perceivers can't distinguish them. This line of thought would individuate shades more according to exact profiles of reflected or emitted wavelengths than is ordinarily done, for if the mixture of wavelengths is different, there will be room for a pair of persons who agree on colors and shades of the usual sort but differ in experimental setups like the Rayleigh anomaloscope in which colored lights are mixed. The technical term for objects which match in exact spectral profile is "isomers." On one version of this view, then, shades would be isomer equivalence classes.

However, the subjective extensionalist has a ready reply: Subjective extensionalists are talking about subjective shades, not objective shades. Perhaps the mixture of lights is not the same objective shade as the aquamarine chip, but if Jack can't distinguish them in ideal circumstances, the two items are of the same Jack-shade. If Jack can't distinguish between red and green, we wouldn't take the representational content of his experience of red as red but rather as something more like a disjunction of red and green. Similarly, assuming that the representational content of Jill's experience of the aquamarine chip is aquamarine, we shouldn't take Jack's representational content of the aquamarine chip as aquamarine-precisely because she can and he can't distinguish the aquamarine chip from the mixture of lights. If the mixture is a different shade than the aquamarine chip, then the content of Jack's representation of the color of the aquamarine chip would be better regarded as the disjunction of the two shades rather than just aquamarine itself. So Jack's and Jill's visual categories are different after all. Thus the subjective extensionalist can withstand an objective difference in shade between the aquamarine chip and the mixture of lights that Jack matches to it. 
Another line of reply to the subjective extensionalist would be to deny that there is any matter of fact as to whether the mixture of lights is the same shade as the aquamarine chip. After all, two normal perceivers in ideal conditions disagree about whether the mixture of lights is the same shade as the aquamarine chip, so how could there be a matter of fact? And since there is no matter of fact, the mixture of lights is not in either Jack's or Jill's extension of the aquamarine category. I regard this reply as correct, but it does presuppose objective color. Again, the subjective extensionalist can insist on subjective (person-relative) color, saying that Jack's and Jill's contents differ according to their extensions, independently of the facts about sameness and difference in objective shade.

My favored reply to the subjectivist extensional conception is that its coherence is dubious. For the extensionalist part of the doctrine depends on conceptions of ideal circumstances and normal perceiver-if one normal perceiver applies and the other withholds a given representation in ideal circumstances, that ensures that the representations differ in content. The notion of normal perceiver is relevant to subjective color in the form of normal state of a perceiver. Even if Fred is highly abnormal by the standards of humanity, still Fred's representations can have idealized extensions. But the idealized extensions will depend on Fred's being in a normal state-for Fred. Fred's applications of color or shade representations while dead drunk won't count. The problem is this: it is unclear that there is any content to optimality of conditions and normality of perceiver independently of what it is to get colors right. That is, it is unclear that subjectivism is compatible with extensionalism. The dependence on objective color is trivial if normality and optimality are given what Crispin Wright calls the "whatever-ittakes" reading: optimal conditions for detecting aquamarine are just the infallibly aquamarine-detecting conditions. ${ }^{28}$ But the same holds in a less direct manner if optimality and normality are given substantive readings.

It is natural to take optimal or ideal (I use these as stylistic variants) circumstances to include a certain intensity of lighting and field and angle of view. And it is natural to take normal state of a perceiver to include no finger pressing on the eyeball (which induces phosphenes, illusions of colored swirls), no electrical stimulation to the cortex and no ingestion of hallucinogenic drugs. But the rationale for including or excluding any such factor involves a conception of objective color and what it is to see things as having the objective colors that they in fact have. There is a famous illusion known as the McCullough Effect. ${ }^{29}$ To prepare yourself to experience the McCullough Effect, look at a pattern of red and black stripes along with green and black stripes at right angles to the first stripes for five or ten minutes. To experience the McCullough Effect, look at a similar configuration of black and white stripes. You will see images of the complementary colors in the white areas even as much as a month later. If the first grid had 
horizontal red stripes, you will see the horizontal white stripes of the black and white grid as greenish. The colors you see in the black and white grid are illusory, hence a perceiver so prepared is not normal. The grid that looks reddish and black is actually white and black, so if you want to see the grid colors as they really are, don't set yourself up for the McCullough Effect. Those who set themselves up for the McCullough Effect are not perceivers in a normal perceptual state, but what makes them not normal is that they will not see a black and white grid of the appropriate size and orientation as black and white. So normality of perceiver only makes sense relative to objective color.

The same point applies to ideal conditions. As Hardin has persuasively argued, there are many different ways of standardizing viewing conditions, and the relevant type of condition depends on what is to be viewed and the purpose of viewing it. For example, some color samples will look to be one color on a light background, another color on a dark background. One remedy is to use a narrow viewing tube. But a narrow viewing tube will be very suboptimal for viewing brown, a color that depends on contrast effects. What makes the tube suboptimal for viewing a brown chip is that the chip is objectively brown, but the normal perceiver won't see it that way in those circumstances. If we cut our conception of color loose from objectivity, it is not clear that there is any substance in the invocation of normality of a perceiver or ideality of circumstances. There are conceptual connections among the issue of the nature of objective color, normality of a perceiver and optimality of conditions of perception. We have no choice but to determine these things together. (I am indebted here to conversation with Tyler Burge.)

There is an obvious subjective-extensionalist response, which can be introduced by considering the debate between those who regard colors as primary qualities against dispositionalists. The primary quality theorist says to the dispositionalist: you say that what it is for an object to be red consists in normal perceivers having a certain response to it in ideal conditions. But ideal conditions are arbitrary given that all there is to something being red is causing a certain reaction in those very conditions. Any conditions would do. The dispositionalist counters that the ideal conditions are only ideal in that it is part of our concept that an object's having a color consists in causing a certain response in those very conditions. And this is the natural response by the subjective extensionalist: We don't need objective colors to anchor our understanding of optimality and normality because the concepts of optimality and normality are supplied by our concepts of color and shade themselves.

But the key questions are beyond the reach of common-sense concepts. Some color judgments are made better in a 2-degree viewing field with a dark surround, others in a 4-degree viewing field with a dark surround. It 
isn't our concepts that tell us that one is more ideal than another for a specific judgment, but rather empirical testing against a background view of what the colors really are. Of course, our concepts are deployed in empirical testing, but that is not the use of concepts that is at issue.

Difficult color viewing tasks such as fine-grained judgments of matching depend on highly specific viewing conditions, often known as "standard conditions," whose details involve empirically determined parameters. Further, it is an interesting fact about the conceptions of standard or ideal conditions that are found in the literature that they differ slightly but significantly from one another. For example, Boynton suggests that ideal conditions involve looking through a hole in a luminous hemisphere that provides the illumination of a cloudy sky at a 45-degree angle at an object placed at the center of a horizontal plane that is rotating at $12 \mathrm{rpm}$, the plane being covered by a 40 percent neutral reflecting surface that suffusely reflects all wavelengths equally. ${ }^{30}$

By contrast, the instructions for viewing Munsell chips stated in the Munsell Book of Color are "that the samples should be placed against a dark achromatic background and "colors should be arranged under North Daylight or scientific daylight having a color temperature of from 6500 degrees to 7500 degrees Kelvin. Colors should be illuminated at 90 degrees and viewed at 45 degrees, or the exact opposite of these conditions.", 31 Does anyone think that such precise viewing angles are to be derived from our color concepts alone without empirical testing? Further, are differences between them to be resolved by appeal to concepts alone? These differences are insignificant for most purposes, but they loom large when we are thinking of perceptual judgments that are at the limit of human capacity. Suppose Jill sees a difference between two chips in one set of conditions but no difference in the other. Do our concepts tell us that one circumstance is more ideal than the other? You may suppose that the way our concepts come in is by dictating that the ideal conditions are the ones in which we make the most distinctions. But what if the two conditions yield the same number of distinctions, just slightly different ones? (See the discussion three paragraphs below.)

Further, even if our concepts supply standard conditions for viewing colored chips, it is doubtful that these considerations would extend to viewing the mixtures of colored lights I have mentioned, much less stars. TV screens, color photos printed in newspapers and rainbows. ${ }^{32}$ Averill tries to answer via a divide and conquer strategy. ${ }^{33}$ In some cases, he seems to claim that our concepts do supply standard conditions, in others, the colors are not what they seem. (Rainbows have no colors, TV screens are the colors of the 3 phosphors, newspaper photos are the colors of the individual dots.) Discussing these issues would take us beyond the scope of this paper, 
though I hope I can rely on a sense that such proposals are prima facie implausible. ${ }^{34}$

You may suppose that the indeterminacies in ideal conditions can be handled by postulating indeterminacies in representational contents. But that raises a different issue, for there is no reason to think that phenomenal character is similarly indeterminate. The burden would then be on the representationist to show that any indeterminacy in representational content is matched by an indeterminacy in phenomenal character.

In thinking about this problem with subjective extensionalism, it may be of use to have an alternative more objective conception at hand. I will attempt to sketch one here that is extensionally based but not subjective.

I spoke of Jack's and Jill's visual categories of red as including or comprising somewhat different shades. What does that come to? I have been speaking of ultra-fine-grained shades as systematized in the densest set of chips that all people with normal color vision can distinguish from one another. The key property of the set of chips is that there are no colored objects that can be discriminated (colorwise) by any normal perceiver from every one of the chips in ideal conditions. That is, every colored object is seen as matching one of the chips by normal perceivers in ideal circumstances. (If a normal perceiver finds something that does not match one of the chips, that just shows the set of chips was incomplete, and the new item or a new chip based on it should be added.) And it would make sense to define ideal conditions and the normality of a perceiver in terms of this requirement. Minimal shades as represented by the set of chips are objective in the sense that they can be agreed upon to be the minimal shades by all normal perceivers. Different normal perceivers may clump the chips differently into broad color categories, but they will all be able to discriminate no fewer and no more shades. Colors such as red and green are sets of shades, though perhaps somewhat different sets for different persons. Let's call the set of ultra-fine-grained chips the Ultimate Color System. As I mentioned earlier, there will be roughly a million chips in such a system. Perhaps there will be ties for the ultimate set. If so, we will chonse one of the tied systems. ${ }^{35}$

In terms of this apparatus, then, Jack and Jill would each classify a set of Ultimate Color System chips as "red" in ideal circumstances, and those sets perhaps would not coincide exactly. That's what I mean by saying that their categories of red comprise or include somewhat different shades. The content of color perception can be defined in terms of this notion of comprising shades. Two color representations are different in content just in case they comprise different shades. One could say that what makes two representations different in content is that they carve out different chunks of objective color space. So my conception has a place for subjective colorbut it is based on objective color. 
Now let us return to Jack and Jill and the aquamarine chip, which, let us suppose, is one of the Ultimate Color System chips. There is a mixture of lights that Jack sees as matching the chip but Jill does not. Then Jack matches the mixture of lights to one of the Ultimate Color System chips whereas Jill matches the mixture of lights to another chip. That is, Jack sees both the chip and the mixture of lights as matching one chip (since the chip matches itself), whereas Jill sees them as matching two chips. For every colored thing is seen by normal perceivers as matching some chip in the Ultimate Color System. The fact that Jill makes a discrimination that Jack does not make does not show that Jill discriminates more shades than Jack. The Ultimate Color System chips include all shades discriminable by normals from one another and Jack and Jill are normal. Thus Jack and Jill have visual representations of aquamarine (or "that chip") with exactly the same representational contents. The mixture of lights is indeterminate in shade, being seen as having one shade by one normal perceiver and as having another shade by another normal perceiver. It is not in the extension of "aquamarine" or of the visual category indicated by "that shade" as applied to aquamarine. So on this conception of shade, the argument against representationism works.

The upshot is that the subjective extensionalist conception has a chance of evading the refutation of representationism. But the subjective extensionalism used in the evasion raises some difficult issues for representationism.

\section{OBSERVATIONS ON THE SEMANTICS OF COLOR TERMS}

I now move to some questions about we should think of the semantics of color terms in the light of the facts of individual variation that I have been discussing. The issues here are closely related to my critique of representationism. We can start with a question: What is the status of unique green? It can t be an objective minimal shade like the Munsell or OSA shades (or the Ultimate Color System). since Jack and Jill will disagree about which chip is unique green, yet both can be correct. And it can't be a phenomenal character. If Jack and Jill are each looking at the shades that they classify as "unique green" (say Green 21 for Jack, Green 22 for Jill), we have no guarantee that their phenomenal characters would be the same.

In order to cope with this problem. I am first going to summarize some views of Sydney Shoemaker's, since they are needed in order to introduce the notion of a phenomenal property. Shoemaker's views will also allow me to sharpen up the representationist position, since his position combines elements of phenomenism with elements of representationism.

Shoemaker is a representationist on one definition of the term. ${ }^{36} \mathrm{He}$ 
holds that when one looks at a red tomato, one's experience has a phenomenal character that represents the tomato as having a certain phenomenal property and also as being red, the latter via the former. On his view, the objects have certain phenomenal properties in virtue of standing in causal relations to experiences which have certain phenomenal characters. ${ }^{37}$ Each phenomenal property of an object can be defined in terms of production by it in certain circumstances of a certain non-representational phenomena! character of experience. (Note that phenomenal properties are therefore causally efficacious.) The view is motivated in part by a consideration of the inverted spectrum. For concreteness, suppose that George's spectrum is inverted with respect to Mary's. George's experience of the apple represents it both as red and as having phenomenal property $\mathrm{Q}$ (the former via the latter). Mary`s experience represents the apple as red and as having phenomenal property P. (George's experience represents grass as green and P, whereas Mary's experience represents grass as green and Q.) What determines that George's experience represents phenomenal property $Q$ is that it has the non-representational phenomenal character $\mathrm{Q}^{*}$; and $\mathrm{Q}$ gets its identity (with respect to George) from the (normal) production of $Q^{*}$. Red can be identified with the production of $\mathrm{Q}^{*}$ in George, $\mathrm{P}^{*}$ in Mary, etc. The phenomenal character $\mathrm{Q}^{*}$ is in a certain sense more basic than the phenomenal property $\mathrm{Q}$, for $\mathrm{Q}^{*}$ is what makes it the case that the experience represent $\mathrm{Q}$. Still, it could reasonably be said that there is nothing in $\mathrm{Q}^{*}$ over and above its representation of $\mathrm{Q}$, and so Shoemaker's view qualifies as representationist about phenomenal character $\mathrm{Q}^{*}$ on my definition. However, there is more to $\mathrm{Q}^{*}$ than the representational content red. Shoemaker's view could therefore be said to be representationist with respect to phenomenal properties but not colors. If two experiences have the same representational content $Q$, then they must both have the same phenomenal character, in this case $\mathrm{Q}^{*}$; so phenomenal character supervenes on the representation of phenomenal properties. But phenomenal character does not supervene on the representation of colors. George and Mary both have experiences that represent red, but one has phenomenal character $\mathrm{Q}^{*}$, the other $\mathrm{P}^{*}$. So if inverted spectra are possible, representationism with respect to colors is wrong. It is that kind of representationism that is at issue in this paper. That is, the argument against representationism in this paper is directed against the view that the representational content of color experience is color content. In my view as well as in Shoemaker's, the phenomenal character of an experience as of red is not exhausted by the representation of what is seen as red.

Now back to the question of unique green. Here are some options:

1. Objective shade. The Benjamin Moore Paint Company has wisely refrained from using "unique" in any of its color names, 
perhaps to avoid any appearance of lack of objectivity as to what color the customer is buying. "Unique green" cannot name an objective minimal shade, since as noted above, Jack and Jill may disagree about which shade it is, yet they can both be correct. Different people would single out different chips as "unique green" from Benjamin Moore samples or from the Munsell or Optical Society of America Uniform Color Space samples even under the most ideal conditions, and no one should choose one of them as more correct than the others. So this is not a live option.

2. Phenomenal Character. If Jack and Jill are each looking at the (different) chips that they classify as "unique green," we have no guarantee that their phenomenal characters would be the same. So unique green cannot be a phenomenal character.

3. Person-relative phenomenal character. "Unique green" names for each of us the phenomenal character we get from a shade that does not appear to have any element of red or yellow or blue. It isn't that unique green is a single phenomenal character as in option 2, but rather that the semantics of at least this color term dictates reference to different phenomenal characters in many pairs of different perceivers. Your unique green is something in your mind; mine is something in my mind. My main objection to this view is one I could have raised to 2: on the face of it, "unique green" is a property of things in the world, not of our minds. We should resist pushing the reference of color terms into the head.

4. Person-relative phenomenal property in Shoemaker's sense. Unique green is a property of objects, a property determined in each of us by the phenomenal character we have (maybe a different one in different people) when something does not appear to have any element of red or yellow or blue. This option has the benefit of 3 over 2 without the problem that 2 and 3 share. I consider this one of the main options worth taking seriously. though I will argue against it.

5. Person-relative shade. Different people use "unique green" to describee somewhat different objective shades each naming a shade that is unique green for them. There is no incompatibility between Jack's assertion and Jill's denial of "This is unique green." There are a number of ways of filling in this idea, notably that "unique green" is interpersonally ambiguous and that it is unambiguous but has a suppressed indexical reference.

I won't consider 1, 2, or 3 further, but both 4 and 5 have some initial plausibility. In order to explain my opposition to 4 , I will have to say a bit more about Shoemaker's reason for postulating phenomenal properties in the first place. As I mentioned, Shoemaker accepts the possibility of inverted spectra. That is an assumption I share. But Shoemaker also accepts what he refers to as "Harman's phenomenological point," namely, that introspection is in the first instance of properties of objects and has no direct access to the 
phenomenal character of color experience. When we try to introspect our color experience, all we succeed in doing is focusing on certain properties of objects. But what are those properties? According to Shoemaker, they can't be colors themselves. Since these properties are introspectible, the inverted spectrum precludes their being objective colors. So they must be properties of objects whose individuation is bound up with the phenomenal character of color experience, viz., phenomenal properties.

I reject phenomenal properties because I reject Harman's phenomenological point. I believe that we can introspect phenomenal character, and hence there is no need to postulate phenomenal properties. An ontology of colors of things plus internal phenomenal characters of our perception of those colors is all that is needed. I think the only grain of truth in Harman's phenomenological point is that when we try to attend to our experience in certain circumstances, we only succeed in attending to what we are seeing, e.g., the color of the apple. But attention and awareness must be firmly distinguished. For example, we can experience the noise of the refrigerator (and be aware of it in that sense) but only notice it or attend to it when it ceases. ${ }^{38}$ Further, as Burge emphasizes, what properties we are aware of depends on what concepts we apply. If we apply experiential concepts to our experiences, we can be aware of the phenomenal properties of those experiences. In my view, the issue of unique green that we are now discussing is the best reason for postulating phenomenal properties, but that motivation can be undermined by a better construal, a matter to which we now turn.

"Unique green" doesn't name a single objective shade since we don't agree on which shade that would be and none of us is privileged with respect to unique green. It doesn't name a phenomenal character since it names something in the world, not in the mind. And it doesn't name a phenomenal property since there is no independent motivation for believing in phenomenal properties in the first place. That leaves the last option above. option 5. One version of option 5 would say that "unique green" is ambiguous, being used by different people in somewhat different senses. Another view is that the phrase is univocal but there is an implicit "with respect to me" to be understood.

Let us consider the following way of thinking of unique green: "Unique green" means shade that doesn't seem to have any blue, red, or yellow in it, for short: green that seems pure. Seems to whom? Seems to a contextually indicated person. On this view, the relativity is a product of the invocation of seeming. Note that this is an intentional property, not a phenomenal character or phenomenal property. This proposal has the virtue of explaining how it can be that the Munsell or OSA shade that is unique green for me isn't for you. The shade that seems to you to have no blue, red, or yellow isn't the shade that seems to me to have no blue, red, or yellow. (It also explains the 
relativity of "unique green" without appealing to any relativity of "green.") Hardin notes that "bluish green" is in the same boat as "unique green," since "bluish green" locates a color relative to unique green. ${ }^{39}$ If Jill says something is bluish green and Jack says it isn't because it is unique green, then it would seem that they can't both be right. There is an obvious construal of "bluish green" along the same lines just given: "Bluish green" means green that seems to have some blue in it. If this is right, bluish green isn't an objective shade either.

In conversation, Shoemaker suggests that color terms have divided reference or unmarked ambiguity, picking out not only colors but associated phenomenal properties. Where Jack and Jill seem to disagree (in ideal conditions), he blames it not on the objective colors or shades they pick out, which are the same, but on their picking out slightly different phenomenal properties. Thus he preserves a common meaning in public language and in idiolects for color words. Shoemaker's suggestion is that if Jack and Jill disagree about whether "green" applies, we should construe the disagreement as concerning a phenomenal property rather than a color, but other uses of "green" pick out the color denoted univocally by both of their "greens." Sometimes color terms are used to indicate colors, other times to indicate phenomenal properties. I disagree with this line of thought for the reason mentioned earlier: I am doubtful about phenomenal properties.

The resolution I favor is to do without the "seems" in the analysis of "unique green." If a certain chip is green that doesn't seem to be at all blue, red, or yellow, then if that color experience is veridical, the chip is green without being at all blue, red or yellow, and that is what it is to be unique green. Unique green is green that is pure, not green that seems pure. How then can we account for the fact that your unique green is different from mine-yet neither of us should be said to be wrong? "Unique green," like "green" has two senses. In fact, the two senses of "unique green" derive from the two senses of "green," "blue," "yellow," and "red." All natural language color terms have a person-relative sense based in the person's visual phenomenology. That is, visual color representations differ from person to person, and there is an at least partially corresponding variation in color terminology. Color terms also have an objective sense based on overlap between people. There are objective colors because there is overlap of personal "greens," "blues," "yellows," and "reds." When we talk about the color something seems to be, we are using person-relative colors. But we sometimes use objective color terms. Suppose you complain to the judge that the color of the stoplight may have been red relative to the policeman, but it was green relative to you. The judge says "Dammit, I don't care about your visual apparatus. The light was red!" This is an (imperfect) objective use. The narrower the color category, the less likely there is to be any overlap. I suppose there is an overlap for "reddish yellow," but maybe not for "on 
the yellowish side of reddish yellow." There is no objective unique green. But there are objective shade names codified by Munsell, OSA, Benjamin Moore, and others, as mentioned earlier. Color terminology is ambiguous but color experience picks out the person-relative properties. When Jack's visual experience represents something as what Jack calls "green," it represents it as having a property that may encompass slightly different chips than the corresponding property represented by another person's color experience.

Jack's visual category of red is subjective in that it differs from Jill's category of red. But it is objective in that it comprises a set of objective color chips (in ideal circumstances). Jill's visual category of red comprises a different set of objective color chips. Jack's unique green is also subjective in that it is different from Jill's, but both are objective in that the chip each picks out as "unique green" has an objective shade. Color terms like "red" or "bluish green" are ambiguous. Jill can use them subjectively to pick out the same intension as her visual category of red or bluish green; and she can also use them objectively to pick out the overlap of all normal perceivers. "Green 126," however, has only an objective sense.

\section{CONCLUSION}

This paper has offered a refutation of one form of representationism. The representationist can evade the refutation by embracing the subjective extensionalist point of view, but that point of view raises its own problems. ${ }^{+1}$

\section{NOTES}

1. FUNCTIONALIST accounts: see Ned Block, "What is Functionalism?" in Readings in Philosophy of Psychology, vol. 1, ed. Block (Cambridge, Mass.: Harvard University Press, 1980). COGNITIVIST accounts: I mean theorists like D. M. Armstrong. A Materialist Theory of the Mind (London: Routledge, 1968), and George Pitcher, A Theory of Perception (Princeton, N.J.: Princeton University Press, 1971), who, roughly speaking, tried to analyze appearing in terms of inclination to believe. See Frank Jackson, Perception (Cambridge: Cambridge University Press, 1977), 37-40, for a convincing refutation. REPRESENTATIONISTS: see below. The definition I give in the text of "qualia" is what is implicit in the literature, but I believe it involves a misconception. In my view, the real issue between friends and enemies of qualia is conceptual. The definition of "qualia" that I favor is: phenomenal features of experience that are not conceptually reducible to the experience's representational, functional, or cognitive features. In my view, qualia could turn out to be, e.g., functional states. I think qualia are entities whose scientific essence is at present entirely unknown, and we therefore cannot rule out a computational-functional theory of them. I have chosen to put my thesis in this paper in more traditional terms to avoid unnecessary conflicts with the way the issues are usually conceived. I will be giving an empirical counterexample to representationism on one 
conception of representationism. Since what is actual is also conceptually possible, the counterexample will work just as well even if "qualia" is defined as I prefer. In addition, I think that the semantics of color terms does depend on actual facts, e.g., whether inverted or shifted spectra are rife. There are many issues about this matter that I cannot go into here, e.g., whether the issues of the semantics of color terms that concern me would be settled by a priori conditionals which are independent of the actual facts. See Ned Block and Robert Stalnaker, "Conceptual Analysis and the Explanatory Gap," Philosophical Review (January 1999).

2. Alex Byrne and David Hilbert, "Colors and Reflectances," in their Readings on Color: The Philosophy of Color vol. 1 (Cambridge, Mass: MIT Press, 1997); Fred Dretske, Naturalizing the Mind (Cambridge, Mass.: MIT Press, 1995); Gilbert Harman, "Explaining Objective Color in Terms of Subjective Reactions," in Philosophical Issues 7: Perception, ed. E. Villanueva (Atascadero, Calif.: Ridgeview, 1996); William G. Lycan, Consciousness and Experience (Cambridge, Mass.: MIT Press, 1996); Michael Tye, Ten Problems of Consciousness (Cambridge, Mass.: MIT Press, 1995); John McDowell. "The Content of Perceptual Experience," Philosophical Quarterly (April 1994). Sydney Shoemaker, "The Inverted Spectrum," Journal of Philosophy 74 (1981): 357-81; Christopher Peacocke, Sense and Content (Oxford: Oxford University Press, 1983); Ned Block, "Inverted Earth," Philosophical Perspectives 4 (1990): 51-79; reprinted in Mind and Cognition. 2d ed., ed. W. Lycan (Oxford: Blackwell, 1999); also reprinted in Ned Block, Owen Flanagan, and Güven Güzeldere, The Nature of Consciousness: Philosophical Debates (Cambridge, Mass.: MIT Press, 1997). Robert Stalnaker, in this volume, "Comparing Qualia Across Persons." Some representationists are satisfied with a supervenience thesis: that phenomenal character supervenes on representational content. But this is compatible with a variety of views on which phenomenal character goes beyond representational content. These views can perhaps be ruled out by appropriate construals of the modalities implicit in supervenience, but I will bypass these issues by taking representationism as an identity thesis rather than as a supervenience thesis.

The representationists I am talking about are externalists. Rey is an internalist representationist about phenomenal character. See his Contemporary Philosophy of Mind (Cambridge: Blackwell. 1997). Shoemaker has a version of externalist representationism. hut one which is representationist only about what he calls phenomenal properties rather than about colors. Shoemaker denies. as do I. that the phenomenal character of an experience as of red is a matter of its representing what is seen as red. Shoemaker's position will be explained further in the last sections of this paper. See Shoemaker, "SelfKnowledge and Inner Sense; Lecture III: The Phenomenal Character of Experience," Philosophy and Phenomenological Research 54 (2) (June 1994): 291-314; and Shoemaker, "Phenomenal Character." Nous 28 (1994): 21-38.

3. See Stephen Palmer, "Color. Consciousness and the Isomorphism Constraint," Behavioral and Brain Sciences (forthcoming) for a detailed authoritative discussion of the empirical issues and Shoemaker, "The Inverted Spectrum." Block. "Inverted Earth." and Byrne and Hilbert. "Colors and Reflectances." for discussion of the philosophical issues.

4. I am assuming objective color and color representations-that is. colors that are intersubjectively available to normal perceivers and color representations that are shared by normal perceivers. Later, I will consider the possibility of subjective or person-relative color categories, those that may vary from person to person.

5. See Christopher Peacocke, A Study of Concepts (Cambridge, Mass.: MIT Press, 1992); T. Crane. "The Non-conceptual Content of Experience," in The Contents of Experience: Essays on Perception, ed. Crane (Cambridge: Cambridge University Press, 1992).

6. Why can 't "unconscious" states have non-conceptual content? If a patch of say orange is presented for a very short exposure and followed by a longer stimulus of random gray characters (a "mask"), then orange can be identified faster than other colors, even though the subject says he saw the mask rather than any color at all. In the psychological lingo. 
masked presentation of a color primes recognition of that color. In some sense, the subject can be said to have perceived the color "unconsciously." Can the representationist allow that the content of an unconscious perception of red is the same as the content of a conscious perception of red? Friends of qualia can allow that states with non-conceptual content, e.g., an image as of something red, can be unconscious in the sense of inaccessible to machinery of reasoning and control of action (access-unconscious in the terminology of Block, "On a Confusion about a Function of Consciousness," Behavioral and Brain Sciences 18 (2) (1995). Reprinted in N. Block, O. Flanagan, G. Guzeldere, eds., Consciousness (Cambridge, Mass.: MIT Press, 1996), and in The Philosophers' Annual, 1996. German translation, "Über ein Missverständis bezüglich einer Funktion des Bewußtseins," in Bew'ußtsein: Beiträge aus der Gegenwartsphilosophie, ed. Thomas Metzinger (Schoningh: Paderborn, 1995). But a representationist who thinks that it is the content of a perceptual state that makes it conscious cannot say this. One way of avoiding the problem is to concede that a pure representationist theory cannot work and that a workable representationism must be combined with functionalism. A conscious state must have a certain functional role as well as a certain kind of representational content. Tye, Ten Problems, holds such a combined representationist/functionalist view.

7. Tyler Burge. Comments on my "Mental Paint," in a book of essays for Tyler Burge, ed. Martin Hahn and Bjorn Ramberg (Cambridge: MIT Press, forthcoming).

8. M. Lutze, N. J. Cox, V. C. Smith, and J. Pokorny, "Genetic Studies of Variation in Rayleigh and Photometric Matches in Normal Trichromats," Vision Research 30 (1) (1990): 149-62.

9. M. Neitz and J. Neitz, "Molecular Genetics and the Biological Basis of Color Vision," in Color Vision: Perspectives from Different Disciplines, ed. W. G. Backhaus, R. Kliegl and J. S. Werner (Berlin: De Greuter, 1998); A figure of 62 percent/38 percent is reported in J. Neitz, M. Neitz, and G. Jacobs, "More than Three Different Cone Pigments Among People with Normal Color Vision," Vision Research 33 (1) (1993): 17-122.

10. J. Neitz and G. Jacobs. "Polymorphism of Long-wavelength Cone in Normal Human Color Vision." Nature 323 (1986): 623-25. The quotation comes from 625.

11. Neitz, et. al, "More than Three Different Cone Pigments," 117.

12. Neitz and Neitz, "Molecular Genetics."

13. Neitz and Jacobs, "Polymorphism." 624.

14. C. L. Hardin, Color for Philosophers, 2d ed. (Indianapolis: Hackett, 1993); L. Hurvich, D. Jameson, and J. Cohen, "The Experimental Determination of Unique Green in the Spectrum," Perceptual Psychophysics 4 (1968): 65-68.

15. Hardin, Color for Philosophers, 193, citing Ralph Evans, An Introduction to Color (New York: Wiley, 1948).

16. Perhaps being categorized as blue by most normal perceivers is enough for being objectively blue. I don't think the difference between most and all will matter for my purposes. I'll stick with all. Note that objectivity in my use of the term is a matter of intersubjectivity. Even subjective, that is person-relative. colors are factual. That is, it is a fact that this object is blue relative to me.

If there are many perceivers who have no identifiable defect in color vision but are rather just extreme outliers who have so little overlap with others so as to reduce the space of objective color to virtually nothing, there will be considerable pressure to regard outliers as abnormal. For if we have to choose between regarding extreme outliers as abnormal and giving up objective color, I think we should and would choose the former.

17. Some may wish to try to avoid this conclusion by insisting that colors are not real properties of things, that our experience ascribes phenomenal properties to physical objects that the objects do not and could not have. See Paul Boghossian and David Velleman, "Physicalist Theories of Color," Philosophical Review 100 (1991): 67-106; reprinted in Readings on Color, ed. Byrne and Hilbert. Recall that representationism as I am understanding it says that the phenomenal character of a visual experience as of red consists in its representing something as red. Are the phenomenal properties (1) colors or (2) phenomenal properties in something like Shoemaker's sense described in "Self-Knowledge 
and Inner Sense" and "Phenomenal Character"? If the latter, the view countenances unreduced phenomenal characters and is therefore incompatible with representationism as I understand it. (See the discussion of Shoemaker's views in the penultimate section of this paper.) The former interpretation is that our experiences represent objects as having colors such as red or orange, but objects do not and could not have those colors. Colors are in the mind, not in the world outside the mind. The point I will be making contains the materials for refuting this view. Briefly, the picture of colors as in the mind rather than in the world has to explain our agreement on which Munsell chip is 4 Red. But how can the Boghossian-Velleman picture on this interpretation of it explain this agreement, given that we have somewhat different experiences, colorwise, when we see that chip? If your experience represents the 4 Red chip the way mine represents the 5 Red chip, how can we explain our agreement on which chips are 4 Red and 5 Red? Perhaps Boghossian and Velleman will say that you and I have different phenomenal characters that represent the same color. But this line of thought only makes sense if phenomenal characters are in the mind and colors are in the world, contrary to the current interpretation of Boghossian and Velleman.

18. Shoemaker, "The Inverted Spectrum."

19. Ibid.; Peacocke. Sense and Content; Jackson, Perception.

20. Hardin, Color for Philosophers.

21. R. M. Boynton, "Insights Gained from Naming the OSA Colors," in Color Categories in Thought and Language, ed. C. Hardin and L. Maffi (Cambridge: Cambridge University Press, 1997). Hardin mentions the estimate that a trained normal observer can discriminate ten million surface colors under optimal conditions and he also notes an estimate that there are about half a million commercially different colors (Color for Philosophers, 182).

22. Hardin criticizes the standard philosopher's way of thinking in terms of responses instead of probabilities of responses. I admit to using the philosopher's standard model here, but I think it is useful if what one is interested in are responses in conditions that are as ideal as can be. For example. let the subject take all day to respond.

23. Byrne and Hilbert, "Colors and Reflectances."

24. See Hardin. Color for Philosophers. especially the new "Further Thoughts" for more on variation in the location of unique green and unique blue. Hardin says that locations of unique green and unique blue actually overlap. That is. there are wavelengths that are classified by some normal people as unique green and by others as unique blue. The criterion for normality here is that of passing standard tests for color deficiency, such as the Ishihara or Farnsw'orth tests. Thus by this criterion of normality, an outlier whose color classifications were very different from 99.9 percent of other normal humans could be normal. As mentioned earlier, I doubt that this notion of normality can be sustained. Note that my argument does not depend on this notion of normality (although some of the studies quoted do use it). Recall, for example. my appeal to fact that the Rayleigh match "most frequently made by female subjects occurs where no male matches." Even if the population includes males and females who differ so much from the average that they should not be counted as normal. it would be true even if they were eliminated.

25. My objection to representationism on the basis of individual variation was arrived at independently of Byrne and Hilbert. I have been giving this argument in classes since I happened to read NIH. "Mixed-Up Genes Cause Off-Color Vision," Journal of NIH Research 5 (February 1993): 34-35.

26. Byrne and Hilbert, "Colors and Reflectances." 273.

27. Ibid.. 274 (my italics).

28. Mark Johnston, "Objectivity Refigured: Pragmatism without Verificationism," in Reality. Representation and Projection. ed. Haldane and Wright (Oxford: Oxford University Press, 1993). 85-130; Crispin Wright. "Realism: The Contemporary Debate-W(h)ither Now?" in Realify, Representation and Projection, ed. Haldane and Wright, 63-84.

29. See the cover of Block. Imagery (Cambridge, Mass.: MIT Press. 1981), or Hardin, Color for Philosophers, pl. 5. 
Block, Ned, Sexism, Racism, Ageism, and the Nature of Consciousness, Philosophical Topics, 26:1/2 (1999:Spring/Fall) p.71

30. Described in Evan Thompson, Colour Vision: A Study in Cognitive Science and the Philosophy of Perception (London: Routledge, 1995), 119.

31. Hardin. Color for Philosophers, 68.

32. Hardin, Color for Philosophers.

33. Edward Averill, "The Relational Nature of Color," Philosophical Review' 101 (3): 551-88.

34. Hardin, Color for Philosophers, xxiv.

35. One qualification: Chips that don't actually look different can be discriminated in a sense if they are adjacent and the border is visible because of contrast. Think of contrast effects as being eliminated in the discrimination of chips.

36. See Shoemaker, "Self-Knowledge and Inner Sense," and "Phenomenal Character."

37. Shoemaker distinguishes between qualitative character and phenomenal character, a distinction which I am ignoring here.

38. See Block, "On a Confusion." for more on this type of case, and Burge, Comments on my "Mental Paint."

39. Hardin, Color for Philosophers, xxiii.

40. I am grateful to Eliza Block, Paul Boghossian, Tyler Burge. Alex Byrne. Susan Carey, Larry Hardin. Paul Horwich, Brian Loar, Adam Pautz, Chris Peacocke. Sydney Shoemaker and Michael Tye for comments on an earlier draft, and I am grateful to the participants in my seminar at the University of Barcelona in June 1999 for their helpful discussion. 